\title{
Service Delivery to Refugees and Immigrants: Toward an Integrated Approach
}

\author{
Perry Romberg
}

In the late 1980s, the changing political environment in the former USSR provided an opportunity for large scale immigration to Canada. Faced with shrinking resources and increased demands for its services, Jewish Immigrant Aid Services (JIAS) changed its traditional format of one-to-one casework to include a group service component. The new service was called the Integration Program. Four program modules were developed which reflected the core settlement service needs of newcomers: instruction in English as a second language (E.S.L.); job preparation; ethnocultural programming; and group counselling. All new clients were placed in small groups of 15 to 20 over a five month period. During that time, each group met weekly for each of the four modules.

This group approach provided basic resettlement services over a short period of time in a very intensive manner. The results of a recent program evaluation indicated that the program enabled JIAS to:

1. Improve its efficiency and service larger numbers of its case load;

2. Provide a strong peer support base via the group approach;

3. Provide resettlement information, guidance and counselling through the professional group leaders; and

4. Provide cultural programs with the host community which have facilitated the initial integration of newcomers into their host community.

\section{Introduction}

Jewish Immigrant Aid Services of Canada received its federal charter on

Perry Romberg, M.S.W., C.S.W., is the executive director for the Toronto office of Jewish Immigrant Aid Services of Canada.
August 30, 1922. The Agency was established and funded by the Jewish community of Canada and acted as its representative in the area of immigration/refugee affairs. In the 70 years since its inception, JIAS has had a long, prestigious history advocating on behalf of immigrants and refugees, and developing quality social service programs to facilitate their resettlement and integration into Canadian society. In many cases, bringing Jews to the safety of Canada and away from the perils of anti-Semitism, has been a central task of JIAS, one which the Agency continues to perform to this day.

In the late 1980s, the political reforms introduced in the Soviet Union by then-President Gorbachev provided scores of people, particularly Jews, with the opportunity to leave the Iron Curtain countries. The history of anti-Semitism in Soviet culture and in the Soviet establishment over the last 70 years of Communist rule is one that has been well documented. Throughout this period, Jewish communities worldwide advocated for the right of Jews and other minorities to freely emigrate from the Soviet Union. By the late 1980s, this right was becoming a reality.

Although Gorbachev and his reforms held out the hope of changing the country for the better, the loosening of state controls in Soviet society also had the effect of unleashing rampant nationalism, and with it, the return of old voices of anti-Semitism, blaming the Jews for the ills of the country. The departure of state sanctioned anti-Semitism allowed the rise of grassroots expressions of hate and mistrust toward the Jewish population, manifested through threats and acts of physical violence. In this environment, many Jews held little hope for their future in the former USSR.
With emigration possible again, JIAS was instrumental in helping thousands of Soviet Jews reunite with their families who had come to Canada years before. The Soviet Jewish population in Toronto numbered approximately 10,000 by the mid- 1980 s. Since early 1988, JIAS has resettled over 5,900 Soviet Jews in Toronto. Faced with the large case load of newcomers, the officers and staff of the Agency were determined to intensify the social service programs being offered, and, in particular, to be involved in the area of integration programming. JIAS defined integration as the step after resettlement-namely, that period during which newcomers establish firm, longterm roots and connections in their host community.

\section{Use of Groups in Resettlement and Integration Programs}

In gearing up for this large wave of immigration, JIAS was faced with a challenge common to many social service agencies, namely, a small staff complement with an unmanageably large caseload. While wishing to provide in-depth services to our newcomers, it was apparent that the traditional casework approach, relying heavily on individual counselling and taking the clinical approach to problem-solving, would not be viable. JIAS viewed immigrants and refugees not as individuals with pathological problems, but as a relatively homogeneous group facing the challenge of adjusting to a new culture and society. In our experience, immigrants and refugees are a hardy group with sharpened survival skills and are experienced at risk-taking. Given these characteristics and similar life challenges, it seemed reasonable to assume that they would benefit from resettlement counselling using a group approach to service delivery. In the 
group environment, the newcomer would benefit not only from the expertise of the professional caseworker, but also from the experience of other peers facing similar challenges.

A group can be seen as a mutual aid system. Specifically, a counselling group is comprised of individuals who need each other in varying degrees to resolve their common problems. Facilitated by a professionalleader, the group becomes a helping system wherein clients rely on each other as well as the staff leader/worker. The group facilitates the creation of a number of helping relationships, namely client-to-client, as well as client-to-worker, and as such expands the ability of the immigrant to receive support from more than one source (traditionally, the resettlement worker). The main objective in group counselling is for the worker to help people help each other.

While a group can be a "mutual aid system," for many immigrants, sharing with strangers in a closed setting is a foreign and intimidating experience. This is understandable in light of the fact that ours is a client group comprised of individuals coming from totalitarian regimes where sharing with strangers was dangerous. However, the initial months of resettlement in new homes and communities, leaves many immigrants feeling isolated and vulnerable.

The experience of being part of a group, especially comprised of immigrants from the same country or region, offers the necessary initial support needed to face the hurdles of starting life over again.

Immigrants and refugees share the common fate of having been forced to leave their homes, families and cultures, in order to start anew. Coming together under the guidance of a qualified staff leader provides an opportunity for them to look at issues and difficulties in the safety of those experiencing similar concerns and problems.

The Family Life Education group approach was chosen because it embraces a "health model." It stresses in- formation sharing, problem solving and the use of group dynamics to create a supportive group environment. Recognizing that the concept of counselling and receiving help from a "bureaucrat" is foreign to our clients, JIAS chose to employ this more structured "educational" framework, as it was less intrusive and easier for our clientele to accept.

It seemed that this group approach had much to offer given the homogeneity of the JIAS clientele. A basic, yet fundamental way that group members help one another is through information sharing. The group members have all had immigration and other life experiences through which they have accumulated knowledge, views and values. By sharing their experiences, members can tap into the ingenuity and solutions of others to help themselves. The group leader also contributes in the exchange of information. Together the group can access a rich resource of relevant and varied information. Moreover, within any group there will be different and opposing views or solutions to a problem. Group members can listen to all points of view and synthesize those which carry most meaning to their particular situation.

As the group solidifies and as an environment of confidence and security is created, sensitive areas of discussion such as family stress/violence, marital difficulties, mourning for country of origin, and despair over the loss of status can be broached. Members hearing the expression of feelings similar to their own from their peers often has a powerful effect; it validates hidden feelings and allows members to see they are not alone, and that their fears and despairs are shared by others going through the same adjustment phase.

Moreover, hearing the accounts and concerns of their peers makes a much stronger impact than being told by a professional that other immigrants experience similar concerns and problems.

Alone and isolated in the early period of arrival, many immigrants feel they are the cause of their current misery. The group environment helps put the initial adjustment period into perspective. Discussion of the experiences of group members, facilitated by the group leader, can demonstrate that many of their problems are externally caused (i.e., socioeconomic conditions, racist attitudes) and are not brought about solely by the immigrants themselves.

Finally, from an administrative point of view the group approach presents an efficient mode of service. While it may be costly to ensure staff are adequately trained in group counselling theory and techniques, the benefits to an immigrant clientele, along with the ability of staff to effectively serve a larger caseload makes this a viable alternative.

\section{The Integration Program}

JIAS surveyed its clients to determine the basic needs to facilitate integration into the community. Four core needs were identified: language training (E.S.L.); casework counselling (psycho-social support); job preparation; and cultural programming which connects newcomers to their ethnic community.

Keeping with the group approach, the Agency decided to provide these services as a integrated package over a five month period. Offered twice a year, all new clients are placed in the program. While new clients do see an individual caseworker for initial screening and any ongoing individual attention, the group program delivers the basic services required.

Clients are placed in small groups of 15 to 20 and move through each service area (module) as a group. By offering an integrated package of services, newcomers are relieved of the burden of having to find or be referred to these necessary programs in different settings. Although delivered over a relatively short period of time, the fact that the newcomers participate in each module as a group week in and week out, makes for dramatic results. Evaluation of the program has consistently shown that the intensity and integrated nature of the program provide 
an environment of safety and security for the newcomers which enables them to begin settling in and feeling more connected to the host community in the early stages of their arrival.

\section{Language Training: English as a Second Language (E.S.L.)}

Groups participating in the daytime program receive 25 hours of language instruction each week, while evening participants receive 12 hours each week. All clients are assessed by standard educational methods for class placement and are taught by a qualified teacher. The curriculum incorporates information and discussion topics relevant to the immigrant and resettlement experience. Teachers meet regularly with our casework group leaders to share material/topics which can be worked on in both venues.

\section{Psychosocial Support Groups}

Each group also participates in a weekly two hour support group led by one of our Russian speaking staff. As described earlier, the format is a Family Life Education model. Settlement information to help the newcomer understand Canadian society and lifestyle is shared. However, the primary objective is to help group members deal with the stress and conflict which results from the radical new changes many are experiencing in their lives. Along with receiving instruction in more practical areas such as banking, police, health, schools, etc., more personal issues are introduced as the group coalesces.

Changes in the family, especially with children, new roles for women in Canada, socioeconomic change and its effect on self-esteem, and mourning for the culture of home are examples of the emotional issues confronted in these groups. Skilled staff leadership is necessary to direct the discussion and use the group dynamics in a productive manner. As well, the group leader should be able to communicate in the language of the group in order to effectively facilitate discussion of such sensitive issues.

\section{Job Preparation}

This module is delivered by staff of the Jewish Vocational Services. Along with basic job hunting skills, newcomers are instructed in résumé preparation and how to conduct oneself in a job interview. However, of significance, is the instruction outlining the differences between job search in a free market as opposed to a controlled one (to which our clientele are accustomed, coming from a Communist regime). Another core objective of this module is to prepare the client psychologically for the probability of underemployment in their first positions. Realistic expectations are set and the accompanying frustration, sadness and anger are dealt with in the group. Individual sessions are also held with each client to develop a personal vocational/educational plan.

\section{Cultural Identity}

Unlike the U.S., Canada does not espouse a "melting pot culture." Rather, it is upheld that Canada grows stronger by supporting the richness of the cultures which comprise the Canadian mosaic. Facilitating a connection between newcomers and their local ethnic group is essential if true integration is to occur. The local ethnic community is a reminder of home, and provides a sense of safety, continuity and connectivity to one's roots. Moreover, the host community can provide many opportunities to facilitate the newcomers' understanding of Canadian culture. Also, host communities can offer support to which newcomers can more easily relate, than would be the case for support offered by a nonimmigrant Canadian.

Finally, most émigré communities want to be actively involved in the lives of newcomers. Developing programs which link newcomers and the "settled" former immigrants expand the newcomers' support network beyond the agency.

In this way, newcomers have the opportunity to make connections with the host community for friendship, job networking and emotional support.
Creating ongoing programs in a community which keeps newcomers and "old timers" connected is very difficult. Organizing the local community and sustaining their commitment is a long term process.

\section{Conclusion}

The emotional upheaval caused by the immigration experience often leaves newcomers, particularly refugees, feeling isolated and detached from their roots. The JIAS Integration Program aims at reversing this sense of fragmentation by consolidating core services under one program and by intensifying these services though the use of a peer group support model.

The group support program has been a particularly valuable source of assistance to the refugees. The trauma associated with fleeing one's home, family and roots-indeed, fearing for one's life and being-has a devastating impact on the refugee and his/her ability to adjust. The group support aspect of the program has offered a place of safety and security to the refugees. They have benefitted from peer support, from the structured discussions of adjustment and related issues, and from the general atmosphere of mutual trust which fosters open discussion of the difficulties associated with fleeing and starting over.

In the JIAS experience, the group approach has proven itself to be administratively efficient. Moreover, evaluation surveys have demonstrated its effectiveness in facilitating early adjustment, consistently demonstrating that the integrative nature and intensity of this program promotes a feeling of safety and security in newcomers. This security leads to a reduction of anxiety and stress, allows newcomers to feel psychologically together earlier on, and in general hastens the mending process.

Ultimately feeling more rooted in the new environment, newcomers are then able to access their inherent skills to begin the climb back to independence and self-assurance-basic ingredients for integration into their new community. 
Refuge • Vol. 13 - No. 9 - February 1994

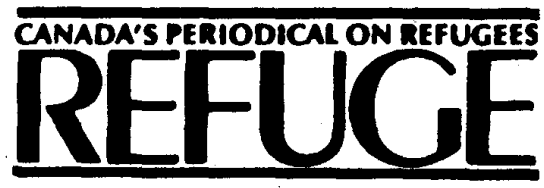

Refuge

York Lanes Press

Centre for Refugee Studies

Suite 351, York Lanes, York University

4700 Keele Street, North York

Ontario, Canada M3] 1P3

Phone: (416) 736-5843 - Fax: (416) 736-5837

Electronic Mail via Bitnet Address:

REFUGE@VM1.YORKU.CA

Postage Paid in Toronto, Canada

Second Class Mail Registration No. 5512

Return Postage Guaranteed

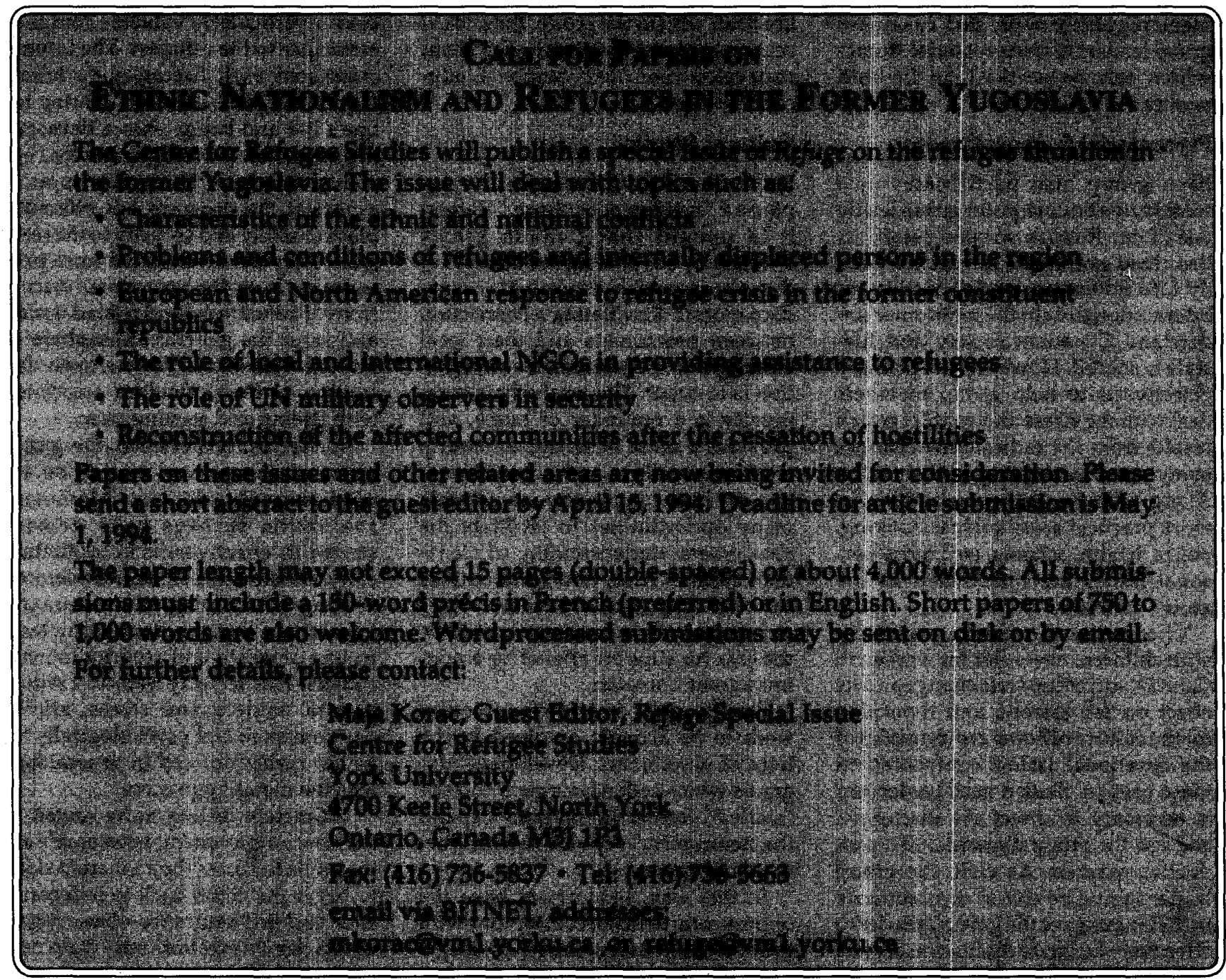

(C) Perry Romberg, 1994. This open-access work is licensed under a Creative Commons Attribution-NonCommercial 4.0 International License, which permits use, reproduction and distribution in any medium for non-commercial purposes, provided the original author(s) are credited and the original publication in Refuge: Canada's Journal on Refugees is cited. 